\title{
The role of cognitive sciences in orthodontic treatments: optimizing the interface between practitioners and new technologies
}

\author{
M. Makaremi \\ Qualified Specialist in Dental and Facial Orthopedics, Independent Practitioner, Researcher in Anthropology
}

\begin{abstract}
New digital technologies have profoundly modified the role and the identity of practitioners in 21 st century orthodontic treatments. Performances issued from the (Computer-Aided Design/Computer-aided Manufacturing) CAD/CAM fabrication proceedings are substituting the technical competence of practitioners, who no longer need to be the craftsmen of made-to-measure therapeutic tools. The real added value of practitioners is found more in their perception, strategy, and cognitive analysis in the clinical situation and their capacity to pass on the information on to the fabrication process. In this new therapeutic structure, cognitive science becomes a precious ally to decode the interface between new technologies and practitioners. However, but beyond the different disciplines on which it is based, exists a path of reflection on the means of optimizing the interface, which relies on the use of new digital technology for the practitioners so that they can be in the center of the conception of the therapeutic project based on CAD/CAM technology.
\end{abstract}

\section{KEYWORDS}

Numeric and digital orthodontics, cognitive science, artificial intelligence, cognitive representation, algorithms, thorough apprenticeship

\section{INTRODUCTION}

In recent decades, our habits have been revolutionized by the advent of digital orthodontics ${ }^{25}$. There is no doubt that today we face the dawn of a revolution. The revolution is evident in the following ways: the advent of imaging, impressions and three-dimen- sional printing; the use of artificial intelligence in the creation of algorithms to facilitate therapeutic proposals (e.g., a virtual setup such as $\mathrm{Clin}^{\mathrm{Check}}{ }^{\circledR}$ ) and the development of industrial processes that facilitate the individualized manufacture

This is an Open Access article distributed under the terms of the Creative Commons Attribution License (http://creativecommons.org/licenses/by/4.0), which permits unrestricted use, distribution, and reproduction in any medium, provided the original work is properly cited. 
of orthodontic appliances and result in profound transformations. These modern technological interventions have transformed not only medical practice 1 but also the entire society, which has experienced a metamorphosis because of new digital technologies9. The rapid rate of these changes raises the question of practitioners' identities and their place in the new orthodontic world. In terms of practitioners' technical roles, these upheavals can undermine specialists because they can lead to the devaluing of human skill. A question can thus be posed-what will be the orthodontist's role in future treatment regimens?

\section{DIGITAL ORTHODONTICS}

\footnotetext{
Designing custom orthodontic equipment using ComputerAided Design/Computer-Aided Manufacturing (CAD/CAM) was made possible by Craig Andreiko ${ }^{7}$ who, while working on the Elan project in the 1990s, developed the first devices for Omcro.

From the inception of orthodontic equipment design, the designer is aware of the inherent challenges of standardization, given the great anatomical variability observed in human beings?

This therapeutic approach is part of the philosophy of personalized medicine: medicine based on patients' individual characteristics, using individualized simulation methods ${ }^{16}$.

In the 2000s, several start-ups, including the Align Technology company, which has since become a multinational company, have increased the access to custom-made equipment designed by industrial processes ${ }^{19}$.
}

However, these transformations can be viewed from a different perspective. The writer, Isaac Bashevis Singer, clarifies this alternative position ${ }^{15}$ : "The main thing is that the orthodontist has nothing to fear from technology." On the contrary, as technology advances, people will become more interested in the capabilities of the human mind. This view, which accords a central role to practitioners in future orthodontics, cognitive sciences can be a precious ally owing to the essential tools provided by this discipline to decrypt and optimize the contribution of human intellect to the therapeutic format of the third millennium.

The simulation of the therapeutic project and orthodontic equipment is based on a closed loop algorithm which determines the therapeutic objective and traces the path of the dental displacements necessary to achieve this objective (Fig. 1). It is therefore based on an artificial intelligence method, in which computer software-e.g., Clin Checkproposes the therapeutic solution after technicians encode the clinical data (particularly, study models with tooth segmentation on the arch) and instructions. The virtual setup is then confirmed by practitioners, and the orthodontic appliance is manufactured by an industrial process and then delivered to practitioners, who ensure therapeutic follow-up.

The therapeutic project therefore originates from an algorithm based on pre-established norms. Published long before the advent of the new technologies, Tweed's analysis ${ }^{23}$ or 


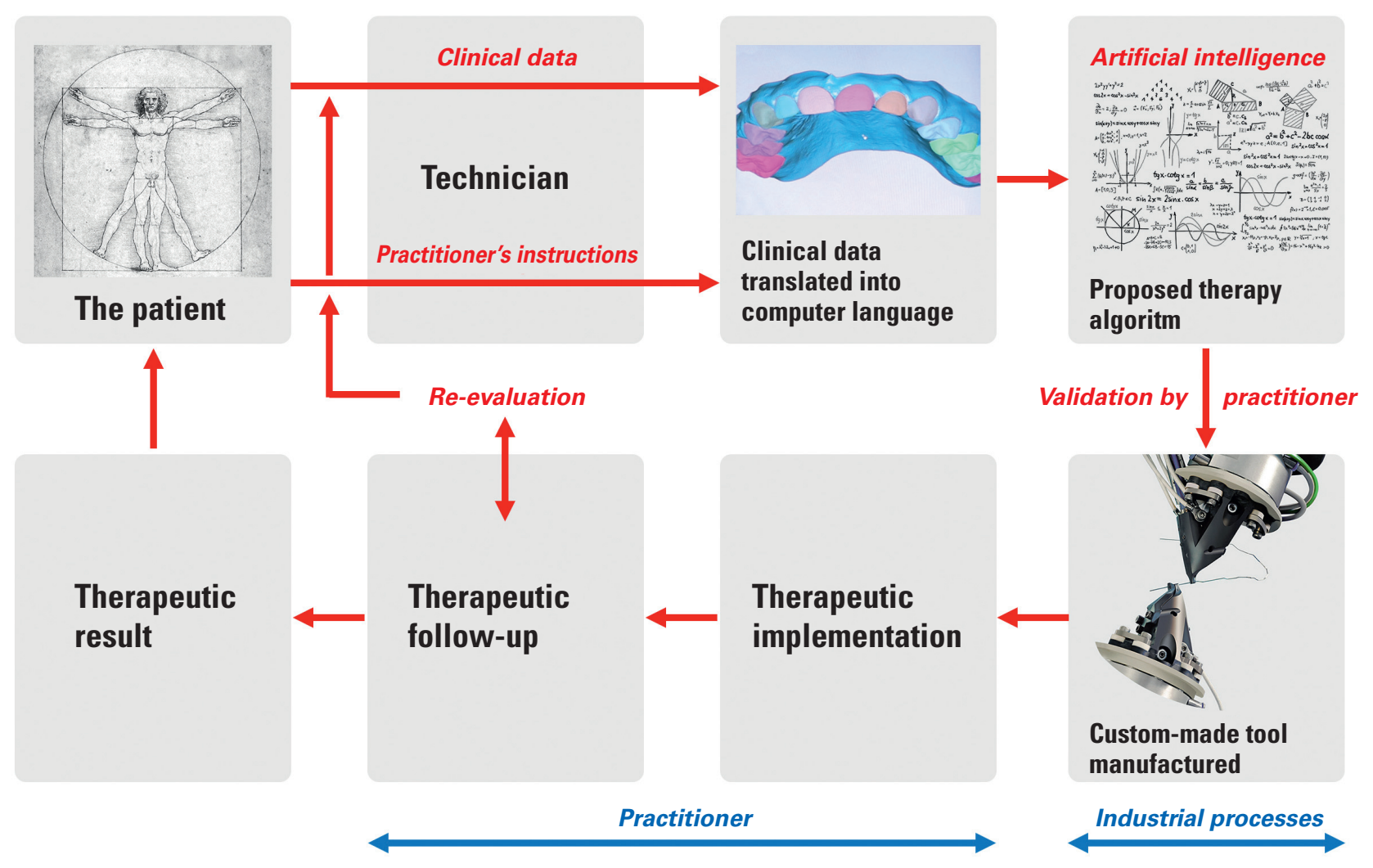

Figure 1

Current design of orthodontic therapeutic tool by CAD/CAM process (industrial process image: Suresmile Robot).

Steiner chevron analysis ${ }^{22}$ can also be seen as algorithms, a finite and unambiguous sequence of operations or instructions to solve a problem. Today, like the past, the essential question remains regarding the confidence that we have in the standards used to establish our treatment plan ${ }^{18}$ : if we consider that a closed algorithm can find an individualized optimum solution ${ }^{24}$, then we can entrust the therapeutic project design to the artificial intelligence. But if we are convinced that there is no magical mathematical formula for achieving the individual optimum and if we believe that the latter is only obtained by sacrificing the symbiosis between the application of scientific norms and data and practitioners' clinical experience, then inevitably a symbiosis must be achieved between the power of the computational, digital, and artificial intelligence tools and the precision of practitioners' clinical perception (Fig. 2). Consequently, the therapeutic project shows the results of this union, and benefits from the progress of digital sciences while keeping the human being at the center. 


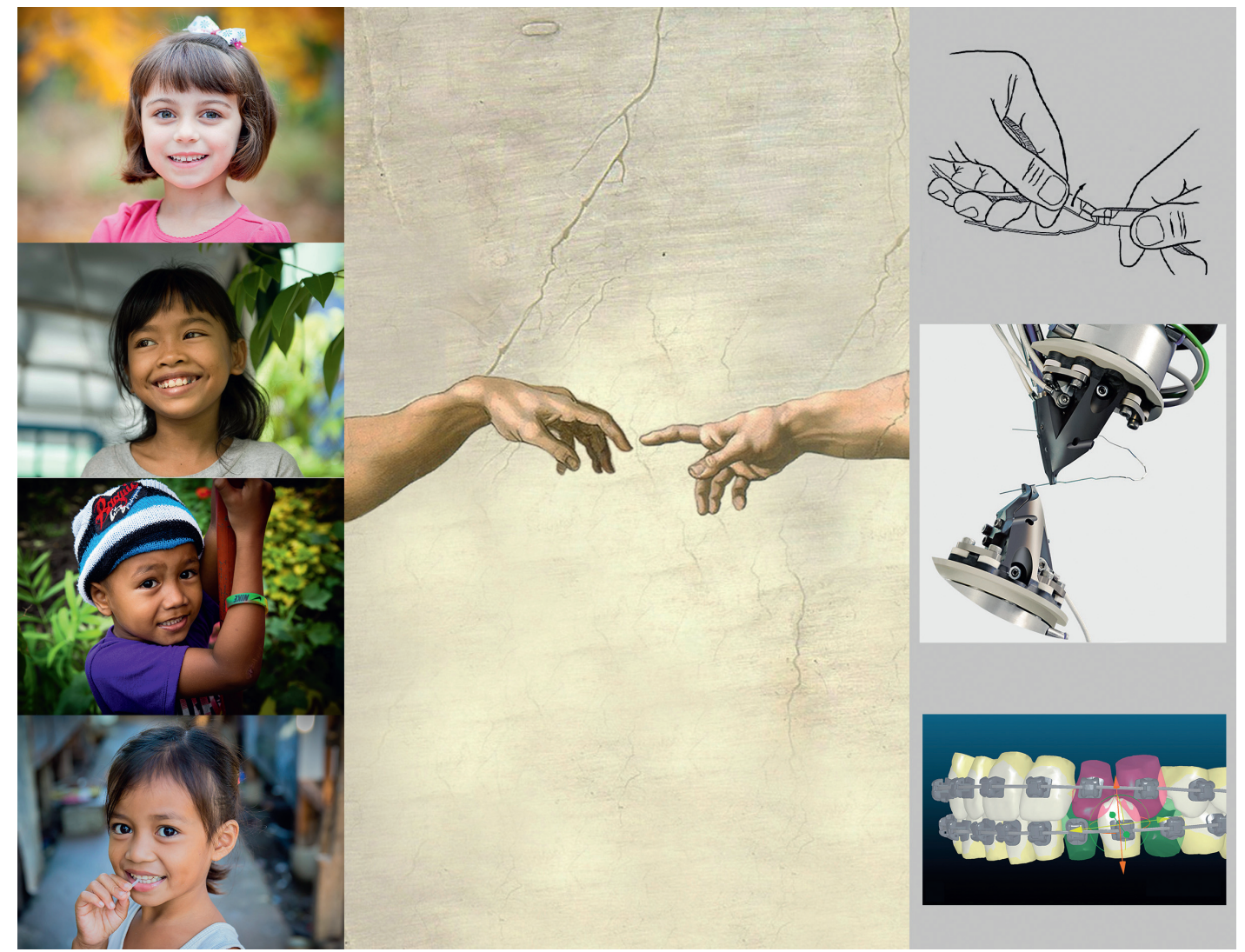

Figure 2

Practitioners must be the link between patients and the custom-made therapeutic tool produced by new technologies.

\section{COGNITIVE SCIENCES}

Cognitive sciences include a set of scientific disciplines devoted to the description, explanation and, if necessary, the simulation of the mechanisms of human or artificial thought and, more generally, of any complex information-processing system capable of facilitating the acquisition, retention, use, and transmission of knowledge ${ }^{14}$. This discipline therefore relies on the study and simulation of phenomena as diverse as perception, intelligence, language, memory, attention, reasoning, emotions, or even consciousness ${ }^{17}$. Started in the 1950s, it is now an extremely vast, interdisciplinary field where the limits and degrees of articulation of the constituent disciplines are still being debated ${ }^{10}$.

Cognitive sciences jointly use data from a multitude of branches of science and engineering, such as linguistics, anthropology, psychology, neuroscience, philosophy, and artificial intelligence. These various disciplines, as seen in the examples cited, can provide a basis for deciphering practitioners' role in orthodontic therapy and their interaction with new digital technologies (Fig. 3).

Linguistic proficiency is essential when the process of manufacturing the customized therapeutic tool is outsourced. 


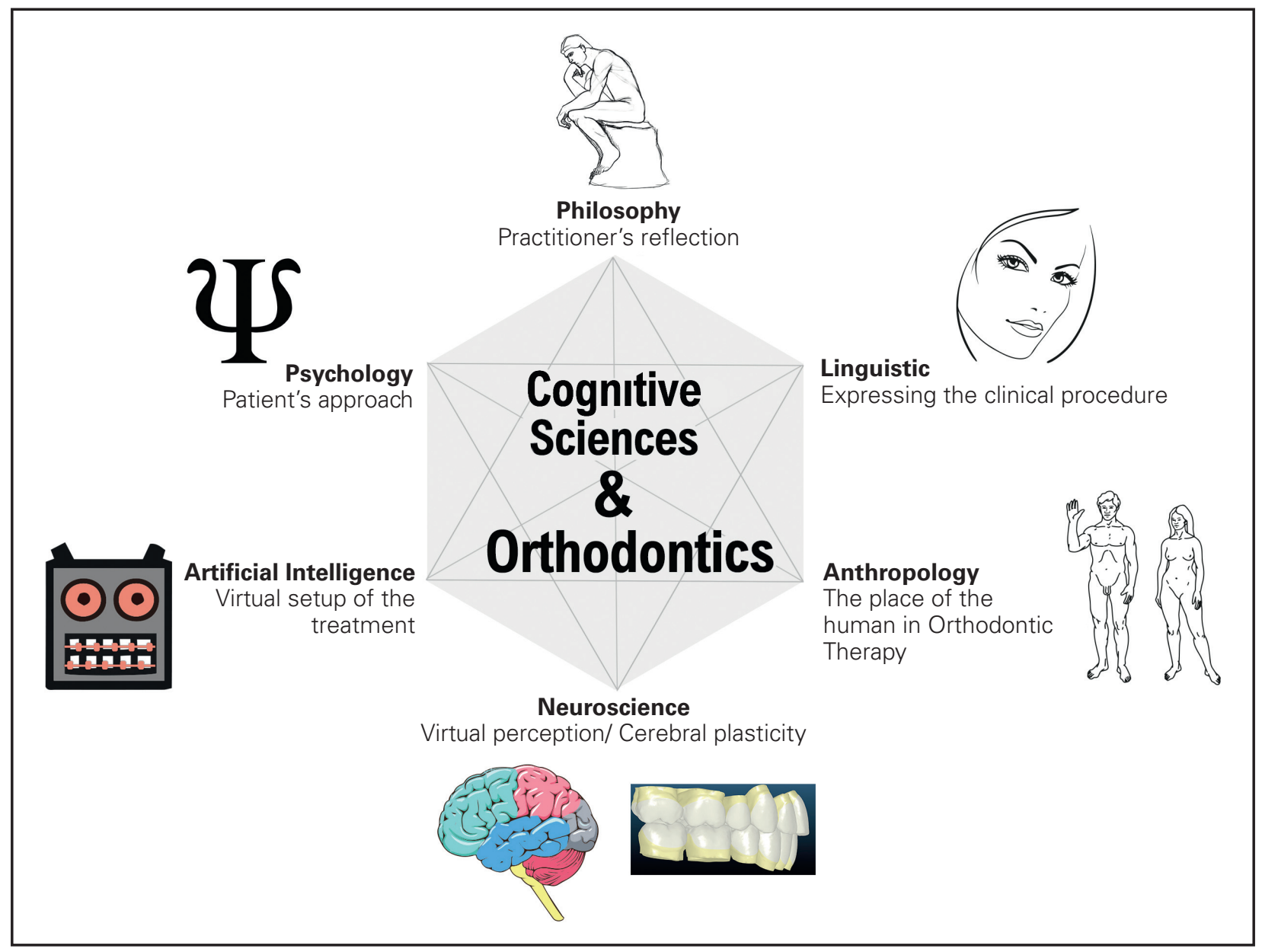

Figure 3

Interactions between the different disciplines of cognitive science and orthodontics.

\section{CONFLICTS IN REPRESENTATION}

Mental representation or cognitive representation is the image individuals have of a situation. It is a confluence of sensations and memory4. Because all human activity is organized according to a specified purpose6, the notion of representation is close to the concept of intentionality. Cognitive psychology believes that all representations are not conscious11. The concept of cognitive representation has also been addressed by the industry, particularly for companies facing particularly high risks (aviation, nuclear, etc.).
Research has been conducted to enable operators to have a mental representation that is closest to reality. This research, based on the theory of communication ${ }^{2}$, has led to an improvement in the ergonomics of humanmachine interfaces.

When practitioners choose a treatment plan and a therapeutic strategy based on the clinical data, they also construct a mental representation of the treatment based on its clinical direction. 
It is only during an orthodontist-confirmed stage that practitioners can engram three-dimensional representations of effective intra-arch and interarch movements at a point confirmed by the orthodontists. They build them based on their therapeutic sensibility and past clinical experiences.

However, practitioners' personality must be sufficiently accommodating to adapt to individual difference in the perception of beauty as well as the emotional motivation of patients' requests. This intuitive representation is a valuable behavioral guide during therapy and contributes to treatments efficiency.

In current practice, when designing customized devices, the manufacturer proposes that a virtual representation of the project be rendered beforehand (Fig. 4), by using Clink Check for instance, based on clinical data and the clear instructions of the practitioner.

Thus, there is a "conflict of representation " between practitioners' mental construction of the project and the virtual setup, created by artificial intelligence. They both trace the therapeutic course and identify the objectives of the same clinical situation, but one is the work of the practitioners' intellect whereas the other is the result of an equation.

If practitioners have not attempted to construct a mental representation of the treatment before viewing the virtual setup proposed by the manufacturer, it will be very complicated to develop one at a later stage.

They then become a slave to the treatment plan produced by artificial intelligence. If they have developed a mental representation beforehand, its compatibility with the virtual setup presents a challenge. The ideal situation is to merge these two representations (Fig. 4) and therefore create a symbiosis that would make it possible to use the advances in digital technology while preserving the predominance of the human element. This symbiosis is necessary because it is essential for medical practice and total mastery of the therapeutic project by the practitioner. This objective requires giving a much more active role to practitioners' cognition in the construction of the virtual setup. This is an ambitious project that requires much more intellectual effort and involvement on the part of practitioners but also shows a greater willingness, on the part of the manufacturer, to effectively cooperate. We would then enter fully into the realm of personalized medicine and the quality of the treatments would be greatly improved and practitioners would be better appreciated.

Today, various obstacles must be overcome to merge the two representations and optimize human-machine interfaces:

- To make clinical data readable to computer software, technical manipulations are necessary. This is particularly valid for the segmentation of the dental $\operatorname{arch}^{13}$, so that the software can recognize and individualize the teeth. It is a tedious job that falls within the purview of the technician, not the practitioner. From the outset, the relationship between the tools of artificial intelligence and those used by the orthodontist is severed. The rapid progress in Deep Learning ${ }^{20}$, which facilitates facial recognition and driverless driving, provides hope that soon the software will be able to encode clinical data on its own, without technician assistance. 


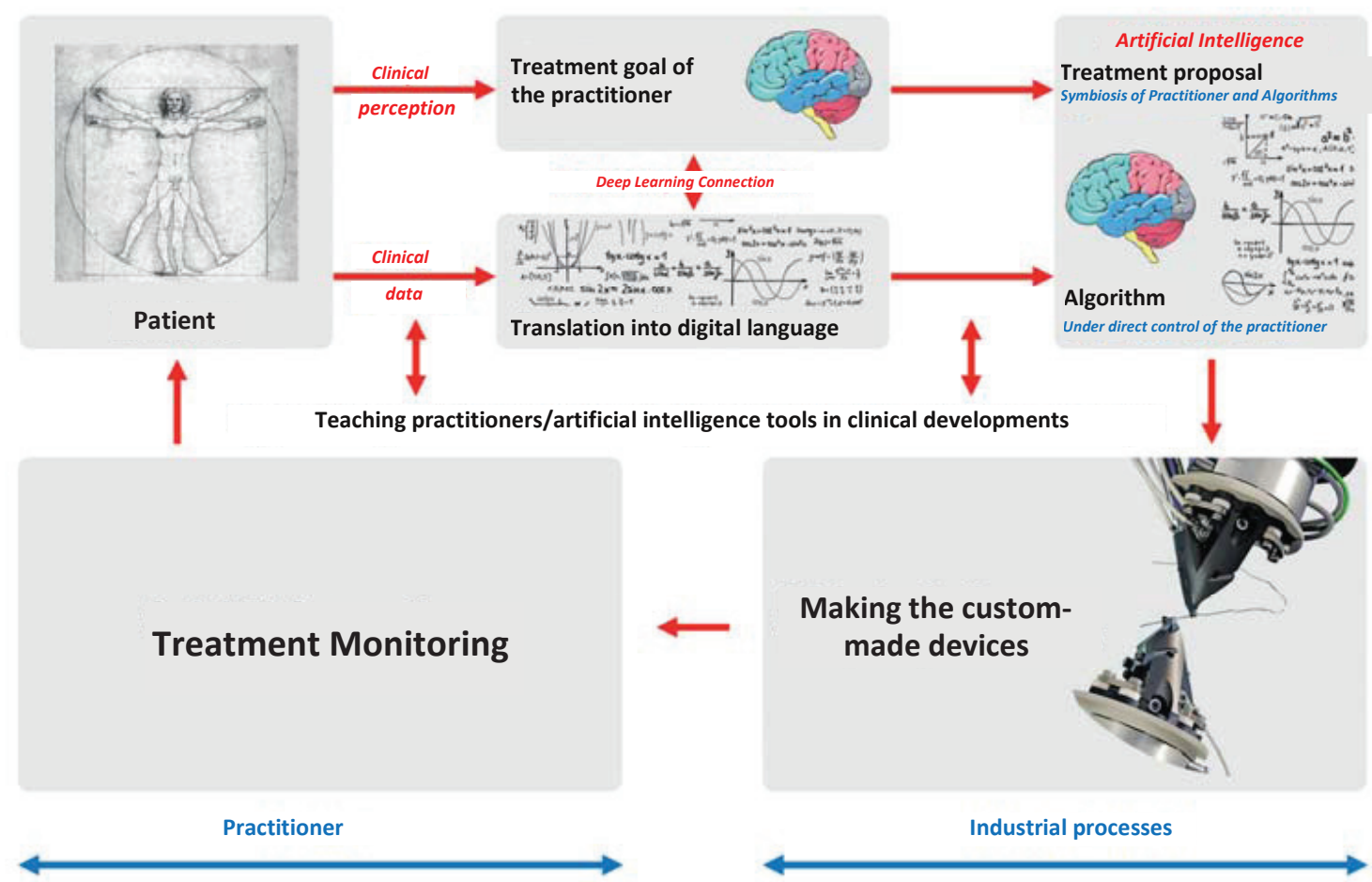

Figure 4

Symbiosis between practitioners and artificial intelligence.

- Another aspect that warrants special attention is the notion of perception. Several neuroscience research studies $^{3,8}$ have noted a difference in neuronal recruitment and brain plasticity (Fig. 5) when comparing the virtual manipulation of an object through a computer screen and its concrete perception and manipulation. We must advance our virtual perception of objects by developing an adequate learning pattern.

- Currently, the conception of orthodontic devices using CAD/CAM technology has been designed by the manufacturers. It is a tremendous step forward in our therapeutic responses. Basically, manufacturers have shaped it so that it can best adapt to their manufacturing processes. It is our responsibility as practitioners to maintain control over the therapeutic strategy and to provide the optimum response, considering the uniqueness of each individual. We can achieve this working closely with the manufacturers, using cognitive sciences to improve human-machine interfaces as well as the connection between artificial intelligence tools and practitioners' intellect. It is also the perfect opportunity to broaden our horizons. The rapid progress of $3 \mathrm{D}$ printing ${ }^{5}$ is a source of hope that practitioners will regain control over the design of the orthodontic devices. 


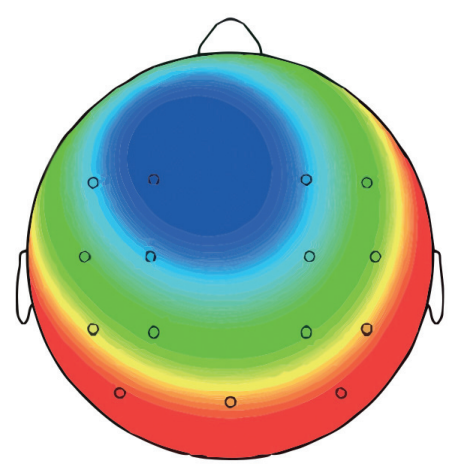

$284 \mathrm{~ms}-329 \mathrm{~ms}$

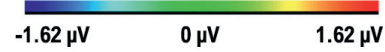

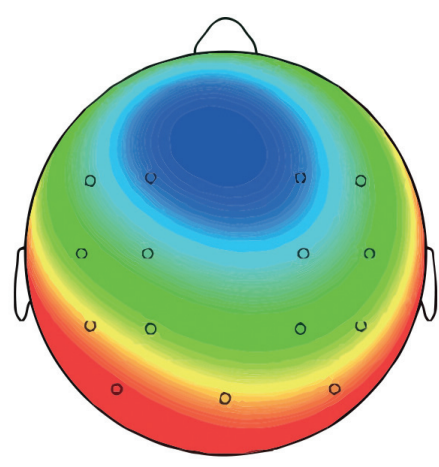

$284 \mathrm{~ms}-330 \mathrm{~ms}$

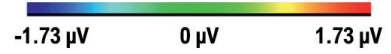

Figure 5

Differential brain activity in a virtual (right) and real (left) perception according to Alami et al.

\section{CONCLUSION}

Reflecting on one of the founding acts of artificial intelligence allows us to illustrate the importance of humanmachine interfaces. During World War II, Alan Turing, an English mathematical genius, invented a machine capable of deciphering the codes of the German army (the Enigma Machine) ${ }^{12}$. At first, it failed because the machine calculations alone were not able to break the codes. It only succeeded in fulfilling its mission when it combined the computing power of the machine with a linguistic analysis of the messages, which was carried out by specialists in the German language, their preliminary work guiding the calculations and increasing the probability that the machine would correctly decipher the codes. Thus, for Alan Turing, success arises from a good connec- tion between human intellect and artificial intelligence. This connection is fundamental in medicine, which deals with the treatment of human beings, and especially in orthodontics where the perception of beauty is subjective.

In conclusion, we must remember that our goal is the cognitive symbiosis of practitioners and artificial intelligence, which will subsequently facilitate the optimal use of new technologies. We can, in this quest, rely on cognitive sciences. Today, many obstacles remain and make the journey difficult and uncertain. But we must keep hope and persevere. In the face of the technological revolution we are experiencing, we quote the words of the historian Robert Rosentone 21 : "The revolution is an attempt to bring dreams to a successful conclusion." 


\section{BIBLIOGRAPHY}

1. Alexandre L. La mort de la mort: comment la technomédecine va bouleverser la médecine. JC Lattès, 2011.

2. Alk EB, Berkman ET, Mann T, Harrison B, Lieberman MD. Predicting Persuasion- Induced Behavior Change from the Brain. J Neurosci 2010;30:8421-8424.

3. Allami N, Paulignan Y, Brovelli A, Boussaoud D. Visuomotor learning with combination of different rates of motor imagery and physical practice. Exp Brain Res 2008;184:105-113.

4. Barsalou L. Perceptual symbol system. Behav Brain Sci 1999;22:577-609.

5. Berchon M. L'impression 3D. Eyrolles, 2013.

6. Berthoz A, Petit JL. Phénoménologie et physiologie de la volonté. Odile Jacob, 2006.

7. Craig A. The Elan and Orthos systems. Interview by Dr. Larry W. White. J Clin Orthod 1994; 28(8): 459-468.

8. Decety J, Jeannerod M, Prablanc $\mathrm{C}$. The timing of mentally represented action. Behav Brain Res 1989;34:3542.

9. Dervin F, Abbas Y. Technologies numériques du soi et (co)-construction identitaires. L'Harmattan, 2009.

10. Dupuy JP. Aux origines des sciences cognitives. La Découverte, 2005.

11. Gallina J-M. Les représentations mentales. Dunod, 2006.

12. Girard JY. La machine de Turing. Editions du Seuil, 1995.

13. Guang $Y$, Yanfang $Y$, Yongdi $Z$, Songhe $W$. A dental model segmentation algorithm for invisalign software. J Chem Pharm Res 2014;6:401-408.

14. Guy T. Dictionnaire des sciences cognitives. Armand Colin, 2003.

15. Lewi H. Isaac Bashevis Singer: la génération du déluge. Cerf, 2001.

16. MathieuT, et al. Champs lexicaux de la médecine prédictive et personnalisée. Annales de Biologie Clinique 2012;70:651-658.

17. Miller GA, Galanter E. Plans and the structure of Behavior. Rinehart Winston, 1960.

18. Philippe J. Nouveaux développements en céphalométrie. Orthod Fr 2013;84(4):343346.

19. Phulari BS. History of orthodontics. Jaypee, 2013.

20. Ranzato M, Poultney C, LeCun Y. Efficient learning of sparse representations with an energy-based model. MIT Press, 2007.

21. Rosentone R. Romantic Revolutionary: A Biography of John Reed. Paperback Editions - Vintage 1981.

22. Steiner C. Importance of cephalometry in orthodontic treatment. Inf Orthod Kieferorthop 1969;1:3-12.

23. Tweed CH. Clinical orthodontics. Mosby, 1966.

24. Vassura G, D'aolja U, Vassura M, Venier O. Proposition pour un nouvel algorithme diagnostique dans un système orthodontique fermé. Le journal de l'Edgewise $2001 ; 44: 1-12$.

25. Vassura $G$, Vassura $M$, Bazzacchi $A$. A shift of force vector from arm to brain: 3D computer technology in orthodontic treatment management. Int Orthod 2010;8:46-63. 